\title{
вмJ Global Health New global surgical and anaesthesia indicators in the World Development Indicators dataset
}

Nakul P Raykar, ${ }^{1,2}$ Joshua S Ng-Kamstra, ${ }^{2,3}$ Stephen Bickler, ${ }^{4}$ Justine Davies, ${ }^{5,6}$ Sarah L M Greenberg, ${ }^{2,7}$ Lars Hagander, ${ }^{8}$ Walt Johnson, ${ }^{9}$ Andrew J M Leather, ${ }^{5}$ K A Kelly McQueen, ${ }^{10,11}$ Swagoto Mukhopadhyay, ${ }^{2,12}$ Emi Suzuki, ${ }^{13}$ Thomas Weiser, ${ }^{14}$ Mark G Shrime, ${ }^{2,15}$ John G Meara ${ }^{2,16}$

To cite: Raykar NP, $\mathrm{Ng}$-Kamstra JS, Bickler S, et al. New global surgical and anaesthesia indicators in the World Development Indicators dataset. BMJ Glob Health 2017;2:e000265. doi:10.1136/ bmjgh-2016-000265

Received 8 December 2016 Revised 3 April 2017 Accepted 4 April 2017

\section{CrossMark}

For numbered affiliations see end of article.

Correspondence to Dr John G Meara; john.meara@childrens.harvard. edu
Although 5 billion people lack access to surgery and anaesthesia care, little systems-level data exist to address this health inequity and social injustice. ${ }^{1}$ Data drive quality improvement processes in business and health systems in high-resource settings, but clinicians and policymakers in low-resource environments have been metaphorically-and often literally-operating in the dark. The challenges to obtaining accurate health systems data involve nearly all clinical delivery platforms in global health and have been well documented and are also relevant to surgery and anaesthesia. ${ }^{2}$ They include insufficient national-level investment in analytics, insufficient donor investment in data collection, little analysis of global health funding streams, limited tools and resources for data collection at the local level, and limited accessibility of collected data to those best positioned to implement data-driven solutions. Such gaps undermine advocacy, as the problems remain invisible and thus fail to inspire political will.

In January 2014, at the inception of a global surgical movement designed to realign stakeholders into a structured approach to surgical systems strengthening, Dr Jim Kim, President of the World Bank Group, challenged The Lancet Commission on Global Surgery (LCoGS) to develop consensus-based indicators and timebound targets to track progress. Sixteen months later, in April 2015, after thorough consultation with clinicians, researchers, hospital administrators and policymakers, the Commission recommended six core indicators to assess surgical and anaesthesia systems strength. ${ }^{3}$ When these indicators (summarised in table 1) are considered together, they serve as basic proxies of surgical health system functioning.

The LCoGS indicators assess multiple aspects of surgical and anaesthesia care delivery within a country. Where are the facilities capable of providing surgical care and how close are they to the populations that need them? How many surgical and anaesthesia providers are present? What quantity of surgical care is provided to a population? What is the quality of the care at its most basic level; namely, how many people die following surgical care? What is the affordability of surgical care? The latter was included because medical expense itself is a major source of impoverishment worldwide.

In formulating these six questions and arriving at specific indicators, decisions had to be made on what measurable aspects of a health system could serve as suitable proxies. In-hospital perioperative mortality eliminates the need for expensive or unavailable outpatient follow-up, could serve as a proxy for safety and provide a benchmark for improvement. Hospitals capable of providing the 'Bellwether Procedures', defined as a laparotomy, caesarean delivery and treatment of an open fracture, were used as a proven proxy for hospitals capable of providing a variety of surgical and anaesthesia capacities. ${ }^{3}$ Finally, the affordability of surgical care was interrogated by calculating the likelihood of it generating impoverishing or catastrophic expense based on local surgical procedure charges and World Bank datasets on population income.

By June 2015, a group of international academic institutions had partnered with the World Bank and the WHO's Global Initiative for Emergency and Essential Surgical Care to collect national-level data on these indicators from around the world. ${ }^{4}$ The authors of this editorial were either (1) core members of the LCoGS with a particular role in drafting the indicators (NPR, SB, JD, SLMG, LH, AJML, KAM, JGM) and/or (2) involved in conceiving or directing this global indicator data collection effort (NPR, JSNK, SB, WJ, SM, ES, TW, MGS, 
Table 1 Data obtained per indicator including total

\begin{tabular}{|c|c|c|c|c|}
\hline & Definition & $\begin{array}{l}\text { Countries } \\
\text { with primary } \\
\text { data available } \\
\text { from LCoGS } \\
\text { report (April 2015) }\end{array}$ & $\begin{array}{l}\text { No. of countries } \\
\text { with new or } \\
\text { updated primary } \\
\text { data obtained }\end{array}$ & $\begin{array}{l}\text { Total no. of countries } \\
\text { with indicator } \\
\text { data (modelled or } \\
\text { primary data) (April } \\
\text { 2016) }\end{array}$ \\
\hline $\begin{array}{l}\text { Indicator } 1 \text { : Access } \\
\text { to timely surgery }\end{array}$ & $\begin{array}{l}\text { Proportion of a population that } \\
\text { can access within } 2 \text { hours a facility } \\
\text { that can do caesarean delivery, } \\
\text { laparotomy and treatment of open } \\
\text { fracture (the Bellwether Procedures) }\end{array}$ & 0 & 14 & 14 \\
\hline $\begin{array}{l}\text { Indicator 2: } \\
\text { Specialist surgical } \\
\text { workforce density }\end{array}$ & $\begin{array}{l}\text { No of specialist surgical, } \\
\text { anaesthetic and obstetric } \\
\text { physicians who are working, per } \\
100000 \text { population }\end{array}$ & $167^{5}$ & 64 & 176 \\
\hline $\begin{array}{l}\text { Indicator 3: Surgical } \\
\text { volume }\end{array}$ & $\begin{array}{l}\text { Procedures done in an operating } \\
\text { theatre, per } 100000 \text { population per } \\
\text { year }\end{array}$ & $66^{6}$ & 33 & 184 \\
\hline $\begin{array}{l}\text { Indicator 4: } \\
\text { Perioperative } \\
\text { mortality }\end{array}$ & $\begin{array}{l}\text { All-cause death rate before } \\
\text { discharge in patients who have } \\
\text { undergone a procedure in an } \\
\text { operating theatre, divided by the } \\
\text { total no of procedures, presented as } \\
\text { a percentage }\end{array}$ & 0 & 16 & 16 \\
\hline $\begin{array}{l}\text { Indicators } 5 \text { and } 6 \text { : } \\
\text { Protection against } \\
\text { impoverishing } \\
\text { and catastrophic } \\
\text { expenditure }\end{array}$ & $\begin{array}{l}\text { Proportion of households protected } \\
\text { against impoverishment and } \\
\text { catastrophic expenditure from direct } \\
\text { out-of-pocket payments for surgical } \\
\text { and anaesthesia care }\end{array}$ & $186^{12}$ & 12 & 186 \\
\hline
\end{tabular}

JGM). Over the next 3 months, a team of 18 researchers contacted 214 of the 215 countries and independent economies recognised by the World Bank (hereafter referred to as 'countries') through email or telephone. A standardised questionnaire was sent to each ministry of health, formal contacts within the United Nations or WHO, embassy or consulate in the United States or Europe, and/or representatives of professional societies representing surgeons, obstetricians or anaesthesiologists. International databases were queried when publicly available. Contacts in 119 countries responded to these queries, 64 of which supplied new primary data pertaining to at least one of the six surgical indicators. Data were incorporated into existing models for surgical and anaesthesia volume and impoverishing and catastrophic expenditure and added to prior datasets for global surgical workforce density. ${ }^{4-7}$

Finally, in April of 2016, after review of the data and its collection process, the World Bank accepted the LCoGS indicators for surgical and anaesthesia system strength into its well-established World Development Indicators dataset. ${ }^{8}$ This development begins to address calls from the international community, including the $\mathrm{WHO}$, to provide a transparent, easily accessible platform for display of global surgical and anaesthesia data to health systems planners, policymakers, researchers, hospital administrators, clinicians or interested members of the public. ${ }^{9}$

Several lessons emerged from this experience, building on known challenges in global health data collection. First, the lack of standard recording guidance at the front line leads to great variability in how surgical and anaesthesia data are collected and reported. For example, facility-level surgical volumes can vary widely based on data-collection decisions on what counts as a surgical procedure, or whether the data are collected from actual operating theatre logs or simple aggregate facility data reports. ${ }^{10}$ Likewise, given that many low-income countries in the world have surgical workforce densities of less than 5 providers per 100000 population, who is included as a 'surgeon', 'anaesthesiologist' or an 'obstetrician' can dramatically impact national workforce density.

Second, actually collating these data-in many places already collected but not centralised or widely reportedwas an equally difficult task. For example, despite indicators that are conceptually simple and accompanied by precise definitions, this effort was unable to produce sufficient data on two of the indicators: access to timely surgery (indicator 1) and the perioperative mortality rate (indicator 4). Two-hour access requires only the location of hospitals within each country and the services that they can provide (ie, can they perform the Bellwether procedures?). Perioperative mortality is a simple national quotient of perioperative deaths over surgical volume, aggregated from facility-level deaths over facility-level surgical volume, and such data are usually available even in the world's lowest resource clinical departments. ${ }^{11}$ However, without international reporting mechanisms for such data, this 
vital information is lost to obscurity, confined to the pages of logbooks and patient charts collecting dust in medical records rooms worldwide. Systems improvement fail to take flight as deficits in systems processes are not identified, contributing to an invisible epidemic of poor access to surgical and anaesthesia services.

The World Bank's commitment to publishing surgical and anaesthesia data in its 2016 World Development Indicators platform is a major milestone for surgical systems evaluation and strengthening. However, achieving independent accountability in surgical systems strengthening will also require a sustained coordinated model for recurrent, accurate data collection. This will require cooperation of national governments who are convinced that the benefits of these data asks outweigh the burden of their collection and the risks of their disclosure. Most of the new data unearthed by our effort came from high-income and upper-middle-income countries that already collected these data but were never asked to share it. ${ }^{4}$ True worldwide progress in transparency will require data collection in lower resourced countries without existing data collection infrastructure. Funders can help by increasing investment in local research workforce, adequately structuring global health development funding to support surgical data gathering and enhancing local information systems infrastructure. Most important, though, it will require the global community to coalesce around a unified process that integrates surgical data into other international health data collection mechanisms. ${ }^{9}$ The WHO is uniquely positioned to lead in this regard, by coordinating with partners to collect data and by encouraging its member states to be active partners in achieving surgical health equity through data-driven surgical health systems strengthening.

\author{
Author affiliations \\ ${ }^{1}$ Department of Surgery, Beth Israel Deaconess Medical Center, Harvard Medical \\ School, Boston, Massachusetts, USA \\ ${ }^{2}$ Program in Global Surgery and Social Change, Harvard Medical School, Boston, \\ Massachusetts, USA \\ ${ }^{3}$ Department of Surgery, University of Toronto, Toronto, Ontario, Canada \\ ${ }^{4}$ Department of Surgery, Rady Children's Hospital, San Diego, California, USA \\ ${ }^{5}$ King's Centre for Global Health, King's Health Partners and King's College London, \\ London, UK \\ ${ }^{6} \mathrm{MRC} /$ Wits Rural Public Health and Health Transitions Research Unit, School of \\ Public Health, University of the Witwatersrand, Johannesburg, South Africa \\ ${ }^{7}$ Department of Surgery, Medical College of Wisconsin, Milwaukee, Wisconsin, USA \\ ${ }^{8}$ Pediatric Surgery, Department of Clinical Sciences in Lund, Division of Pediatrics, \\ Lund University, Lund, Sweden \\ ${ }^{9}$ Emergency and Essential Surgical Care Programme, World Health Organization, \\ Geneva, Switzerland \\ ${ }^{10}$ Vanderbilt Anesthesia Global Health \& Development, Nashville, Tennessee, USA \\ ${ }^{11}$ Department of Anesthesia, Vanderbilt University Medical Center, Nashville, \\ Tennessee, USA \\ ${ }^{12}$ Department of Surgery, University of Connecticut School of Medicine, Hartford, \\ Connecticut, USA \\ ${ }^{13}$ Development Economics Data Group, World Bank Group, Washington, DC, USA \\ ${ }^{14}$ Department of Surgery, Stanford University, Palo Alto, California, USA \\ ${ }^{15}$ Department of Otolaryngology and the Office of Global Surgery and Health, \\ Massachusetts Eye and Ear Infirmary, Boston, Massachusetts, USA \\ ${ }^{16}$ Department of Plastic and Oral Surgery, Boston Children's Hospital, Harvard \\ Medical School, Boston, Massachusetts, USA
}

Correction notice This article has been corrected since it was first published. The first author is now correctly cited as 'Raykar NP'.

Acknowledgements The authors would like to acknowledge the contributions of all those who contributed to the consultative process of The Lancet Commission on Global Surgery that led to the development of the indicators discussed in this manuscript. The authors would also like to recognise the countless individuals across governments, academic institutions and NGOs worldwide that contributed data to this effort. Finally, we would like to specifically recognise the tireless efforts of the research team that collected and collated the data: Yihan Lin, Saurabh Saluja, Rachel Yorlets, Gabriel Toma, John Rose Jr, Jonathan Scott, Geoffrey Anderson, Allison Silverstein, Benjamin Massenburg, Emily Bruno, Hillary Jenny, Isobel Marks, Lenka IIcisin, Rachita Sood, Sristi Sharma, Adam Lantz, Anton Jarnheimer, Hampus Holmer, Erik Omling, Micaela Esquivel, Ian Matthews, Sean McIntyre and Tarsicio Uribe-Leitz.

Contributors NPR, JSNK, JGM conceived the study and study design. NPR and JSNK led the data collection and collation efforts along with the research team at PGSSC (see acknowledgements). SB, TW, MGS, AJML, LH provided technical input on indicators for data collection needs. WJ, ES, and JD provided strategic advice on advancing the indicator adoption within the global health agenda. NPR, JSNK and JGM wrote the first draft of the manuscript. All authors were involved with critical editing, revisions and approved the final manuscript.

Funding This research did not receive specific grant funding from any funding agency in the public, commercial or not-for-profit sectors.

\section{Competing interests None declared.}

Provenance and peer review Not commissioned; externally peer reviewed.

Data sharing statement All obtained data or modelled data are publicly available on the World Development Indicators website.

Open Access This is an Open Access article distributed in accordance with the Creative Commons Attribution Non Commercial (CC BY-NC 4.0) license, which permits others to distribute, remix, adapt, build upon this work non-commercially, and license their derivative works on different terms, provided the original work is properly cited and the use is non-commercial. See: http://creativecommons.org/ licenses/by-nc/4.0/

(C) Article author(s) (or their employer(s) unless otherwise stated in the text of the article) 2017. All rights reserved. No commercial use is permitted unless otherwise expressly granted.

\section{REFERENCES}

1. Alkire BC, Raykar NP, Shrime MG, et al. Global access to surgical care: a modelling study. Lancet Glob Health 2015;3:e316-23.

2. Committee CRS. The roadmap for health measurement and accountability. World Health Organization, World Bank, United States Agency for International Development, 2015.

3. Meara JG, Leather AJ, Hagander L, et al. Global Surgery 2030: evidence and solutions for achieving health, welfare, and economic development. Lancet 2015;386:569-624.

4. Ng-Kamstra J, Raykar N, Lin Y, et al. Data for the sustainable development of surgical systems: a global collaboration Report from the Lancet Commission on Global Surgery, September. 2015 http:// www.lancetglobalsurgery.org/indicators.

5. Holmer H, Lantz A, Kunjumen T, et al. Global distribution of surgeons, anaesthesiologists, and obstetricians. Lancet Glob Health 2015;3(Suppl 2):S9-S11

6. Weiser TG, Haynes AB, Molina G, et al. Estimate of the global volume of surgery in 2012: an assessment supporting improved health outcomes. Lancet 2015;385(Suppl 2):27.

7. Rose J, Weiser TG, Hider P, et al. Estimated need for surgery worldwide based on prevalence of diseases: a modelling strategy for the WHO Global Health Estimate. Lancet Glob Health 2015;3 Suppl 2:S13-20.

8. World Development Indicators World Bank Gr. 2016. http://data. worldbank.org/indicator (accessed 1 Jul 2016).

9. WHO. Global Reference list of 100 Core Health Indicators, 2015. World Health Organization, 2016.

10. Stewart B, Khanduri P, McCord C, et al. Global disease burden of conditions requiring emergency surgery. Br J Surg 2014;101:e9-22.

11. Watters DA, Hollands MJ, Gruen RL, et al. Perioperative mortality rate (POMR): a global Indicator of access to safe surgery and anaesthesia. World J Surg 2015;39:856-64.

12. Shrime MG, Dare A, Alkire BC, et al. A global country-level comparison of the financial burden of surgery. Br J Surg 2016;103:1453-61. 